\title{
Retrospective on aerodynamic research with infrared imaging
}

\author{
by E. GARTENBERG (*)
}

(") Old Dominion University, Norfolk, Virginia 23529-0247, USA.

\begin{abstract}
Infrared imaging used in aerodynamic research evolved during the last 25 years into a rewarding experimental technique for investigations of body flow field viscous interactions, such as heat-flux determination and boundary-layer transition. The technique of infrared imaging matched well its capability to produce useful results with the expansion of testing conditions in the entire spectrum of wind tunnels, from hypersonic high-enthalpy facilities to cryogenic transonic wind tunnels. With unique achievements credited to its past, the current trend suggests a change In attitude towards this technique: from the perception of it as an exotic, project-oriented tool, to the status of a routine experimental procedure.
\end{abstract}

This review is an updated version (containing about 40 more references) of "Twenty-five Years of Aerodynamic Research with IR Imaging," a survey by Ehud Gartenberg and A. Sidney Roberts, Jr., presented at Thermosense XIII, an international Conference on Thermal Applications and Image Diagnostics, SPIE 1991, and published in the Journal of Aircraft, Vol. 29, No 2, AIAA, March-April 1992 [1].

\section{Abbreviations used for establishments}

$\begin{array}{ll}\text { AEDC } & \text { Arnold Engineering and Development Center, USA } \\ \text { DFVLR } & \text { Deutsche Forschungs-und Versuchsanstalt fur Luft-und Raumfarht, Germany } \\ \text { DLR } & \text { Deutsche Forschungsanstalt fur Luft-und Raumfarht, Germany } \\ \text { NASA } & \text { National Aeronautics and Space Administration, USA } \\ \text { ONERA } & \text { Office National d'Etudes et de Recherches Aérospatiales, France } \\ \text { TSAGI } & \text { Jukowski Central Aerohydrodynamics Institute, Moscow, Russia }\end{array}$

\section{Introduction}

Throughout history, aeronautical engineers faced the need to know more about boundarylayer flows, or ignoring the need, were forced to pay the price. At times, the capability to define and integrate boundary-layer effects in a new design may impact on the success of an entire project. The commercial introduction of infrared (IR) imaging systems in the mid-sixties opened the possibility to visualize viscous interactions between a body and the surrounding air flow by mapping the surface temperature distributions on configurations of interest. The momentum and heat exchange occurring across the boundary layer were related classically through the Reynolds analogy [2]. Invoking this analogy, surface temperature distributions are known to contain information related to both the heat transfer and the skin friction processes occurring at the wall. Therefore, the capability of IR imaging systems to produce in real-time thermograms that can be interpreted both globally and locally makes them attractive for skin friction and heat transfer aerodynamic studies.

Space exploration activities sparked interest in high-supersonic and hypersonic flight, and Inevitably motivated the need to measure and define thermal loads. Most notable are the reentry conditions of the Space Shuttle. In the subsonic and transonic regimes, the increase in fuel prices in the early seventies had a deep impact on the air transportation industry. The response 
to the challenge of improving flight economy of passenger airplanes was focused initially on power plant efficiency. Later, the attention turned toward the aerodynamic efficiency through drag reduction, with the friction component getting much attention.

The resurrection and the success of activities addressing all flight regimes depend critically upon the evaluation and understanding of the viscous flow effects. In the supersonic and hypersonic regimes, the boundary-layer status affects both the friction drag and the thermal loading of the structure, two items of high consideration in any design. In the sub- and transonic regimes, sustaining laminar flow over a significant part of the wings is a major challenge of current aerodynamic interest.

Despite the significant potential IR imaging systems demonstrated for aerodynamic research, the method was not widely accepted and recognized for its full capability until relatively recently. Two problems delayed acceptance of the method in its earlier stages of development. The first was a lack of an easily accessible capability to store and manipulate data. This drawback was naturally solved with the commercial introduction of video cassette recorders (VCRs) and personal computers. The second problem was the realization that the temperature information contained on thermograms results from a multi-faceted process comprising aerodynamics, heat conduction, geometry and radiation [3]. Therefore, the interpretation of thermograms in an aerodynamic sense and the extraction of quantitative data may, at times, require analysis involving disciplines that are not immediately related to aerodynamics.

The reduction of the experimental data, from temperatures to heat flux distributions via the thermal response of the substrate, can be simplified if the physical reality can be modeled mathematically based on assumptions leading to analytical solutions. At one end are models made of thermal-insulating materials. In this case, it is assumed that deep in the substrate there is a layer that virtually keeps its temperature constant throughout the measurement, if its duration is shorter than the penetration time of the thermal wave. This case is known as the semi-infinite slab model, for which the heat conduction equation can be solved analytically for the heat flux as a function of the transitory surface temperature distribution. At the other end, there are hollow, thin-skin models, where it is assumed that the heat flux is uniformly absorbed indepth the material with the temperature changing uniformly across the model skin. This case can be approximated by the thin-skin model of the thermal energy equation. In between these two extreme cases, there is the general case, where the particular details of the model construction may affect the surface temperature distribution construction; e.g., the filler or the spar underneath the skin. It follows that understanding the direct and indirect factors influencing an experiment and its results is critical in determining the data reduction technique. As it can be noticed, designing aerodynamic experiments based on IR imaging and extracting data from the thermograms are very challenging processes.

Utilization of the technique has yielded a wealth of experience and aerodynamic results, but the subject has not been reviewed adequately. This paper is a wide ranging review of the applications IR imaging has seen in aerodynamic research. It should benefit in particular those individuals considering using this method. After a brief description of IR imaging systems, overview papers describing and analyzing the IR imaging technique for aerodynamic research will be mentioned. Attention will then turn to super- and hypersonic, and in turn sub- and transonic applications; two areas where these systems made distinctive contributions. The survey will then proceed to some specific applications in flow visualization, propulsion, fluid mechanics and heat transfer. Before concluding, we shall take a quick look at current trends and expected developments in the applications of IR imaging to aerodynamic research.

\section{IR imaging systems and data processing}

Most of the commercial IR imaging systems are similar in concept to those built 25 years ago. A single detector, usually cooled by liquid nitrogen, is exposed to the incoming radiation from 
the target on which the objective lens is focused. To obtain an image of the objective lens field of view (FOV), the camera scans the scene both horizontally and vertically, with rotating prisms or mirrors, producing the display lines for the video display. The area projected at any single time on the detector is subtended in the instantaneous field of view (IFOV). The output of the detector is transmitted to a black-and-white video display, where lighter shades are associated with higher temperatures. Usually, a single pixel displays the sensor output from one IFOV. To give some specific numbers $[4,5]$ commercial imagers are sensitive to IR radiation either in the 3- to 6-micrometer (short wave) or in the 8- to 12-micrometer (long wave) bands, also identified as infrared atmospheric windows. As indicated by the Plankian curves of black-body radiation, shorter wavelength imagers are better adapted to scan high-temperature targets and vice versa. The field-of-view of commercial objective lens ranges between 2.5 to 40 degrees. One complete scanning of a scene is called a field. To improve the visual quality of the display, two or four fields are usually interlaced to produce a frame. Thus, the camera produces fields, but the human eye perceives frames. A field has usually fewer than 200 lines, each line having usually less than 200 pixels. The scanning rate may vary between 25 to 60 fields per second. GAUFFRE and FONTANELLA [6] give a particularly concise and useful description of IR imaging systems that introduces the reader to camera figures of merit, including sample calculations.

The systems can be connected to VCRs for analog recording and playback and to personal computers equipped with dedicated software for digitizing, storing, and processing of individual fields or frames. A key feature of such software is the gradual assignment of artificial colors (from black through blue, green, and so on to red, yellow, and white) for corresponding gray shades in the original image, thus producing a visual sensation of the temperatures over the scanned target. Recent IR imaging models have a false coloring option built in their display units. Under some circumstances, the thermograms may have to be enhanced when their quality is not adequate for data interpretation or presentation. Simple ad-hoc methods, such as averaging frames or images integration may produce satisfactory results [7]. In more problematic cases, more involved processing methods are required, such as smoothing contours and time-based interpolation [8].

As it frequently happens, the information contained on a thermogram may not make sense to the experimentalist, who will be constrained to evaluate the actual performance and limitations of the IR imaging and data acquisition system. In those rare cases where the target temperature distribution is considered well-behaved and known, the system may be evaluated on an inputversus-output basis [9]. In other cases, specific performance functions, e.g., the Modulation Transfer Function (MTF) of the system may have to be evaluated, to account for missing information and allow data restoration $[10,11]$.

In most aeronautical applications, the camera is installed either outside the wind tunnel, scanning a model in the test section, or inside an airplane cabin or cockpit, scanning the wing. For the radiation to pass through, the wind tunnel, or the airplane, needs special windows transparent to $I R$ radiation. A large selection of commercial, IR transparent materials is available [12]; however, the choice will depend upon the transmittance in the waveband of the specific sensor used, mechanical considerations, environmental compatibility, and cost. Antireflective coating may improve the transmittance of some of these materials at the expense of the reflectance.

\section{Method reviews}

Some of the papers documenting aerodynamic or fluid mechanics experiments feature lengthy introductions describing IR imaging systems, data acquisition and processing hardware, specific peripherals, theoretical underlying principles, general and specific applications, etc. While the main value of the papers lies in the specific work the authors have done, some of them are a good starting point for forming an idea about this technique [10, 13-28]. Some references document studies that were repetitively presented with additions, changes and refinements. 
These successive publications present before the reader the development of the technique, and they give the feeling of the obstacles that were overcome in gaining its mastery and implementation. Some of the above references originated in lecture notes and were published later elsewhere.

\section{Super- and hypersonic studies}

The first documented use of IR imaging in aeronautical research was reported by THOMANN and FRISK [29] of the Aeronautical Research Institute of Sweden. In a wind tunnel experiment performed at $\mathrm{Mach}=7$, the temperature distribution on an elastomeric paraboloid was measured as it evolved in time. From the temperature rate of change, the heat flux at the model surface was deduced using the semi-infinite slab solution [30] for the unsteady heat conduction equation. The short test run (seconds) combined with the low thermal diffusivity material justify use of that solution. This data reduction concept was borrowed from the fusible paint technique [31] and it is still in use. The experiment showed the $I R$ imaging to be as accurate as other competing techniques for heat-flux determination, with the advantage that without requiring surface preparation before or in between runs, it is quite expedient. More than a decade later, BALAGEAS and ORY [32] proposed a data reduction method that incorporated the finite thickness of the skin and the boundary conditions at the internal wall, expanding the applicability of the technique to thin-skin models.

After this technique was shown to work, there were more attempts to evaluate and improve it, e.g. scanning the model against a water-cooled plate to reduce the background radiation noise [33]. However, for a few years the method was far from being productive enough to be directly applicable to project designs. COMPTON [34] at NASA Ames Research Center realized that the bottleneck of the technique was the data acquisition, storage and processing. One should realize that the heat-flux distribution is calculated from the temperature readings on a pixel-by-pixel basis that was generated at rates of approximately 88000 IFOVs per second. The solution was devised to record the data on an analog tape, to digitize and read it into a computer for processing, and thereafter to display and plot the results. This engineering concept set the pattern for similar systems to this very day. Automating the data processing system gave access to all the information produced during a test. In particular, it was understood that monitoring the history of the heating rate for relatively long periods of time could indicate if the boundary-layer transition front moved on the model during the test.

In 1973, the Arnold Engineering Development Center (AEDC) embarked on a large-scale program to develop the capability of extensive heat transfer testing in the hypersonic regime with an IR imaging system [35, 36]. The von Karman facility was designated for that purpose, and engineering modifications were made to allow hosting an IR imaging system for test series that extended over long periods of time. An automated data processing system was developed that accepted input from the IR camera, thermocouples on the model, and temperature and pressure probes providing the operational parameters of the wind tunnel. In parallel, materials used for model manufacture were screened for compatibility with the technique and the environment, and their thermal and radiative properties were documented. Accurate numerical values of these properties are critical for processing the output data from the IR imager, and deducing of the temperature distributions on the model. To assess the accuracy of the technique, calibration procedures were developed, the repeatability of the measurements was evaluated, and a measurement error model was implemented [37, 38]. The results were also confirmed by other experimental means and were found to agree well with theoretical predictions. On the negative side, it was found that step changes in the temperature distribution could not be resolved, the response displaying smear or blur of the change over a few adjacent pixels. Moreover, the camera displayed a consistent measurement error when the target temperature gradient exceeded a certain value. These shortcomings were blamed on the relatively large size of the IFOV of the imager, but this aspect was not pursued enough to a full understanding. While 
a smaller IFOV will allow a better capture of abrupt changes in the temperature distribution, the blur effect will always occur because of the Optical Transfer Function (OTF) of the camera.

The infrastructure and expertise developed at AEDC in the 1970's were used to measure convective heating rates on a 0.04 -scale model of the Space Shuttle orbiter under flow conditions occurring during the re-entry phase. The test flow conditions were typically: Mach $=8$, lemperature $1300 \mathrm{R}$, Reynolds number $0.5 \times 10^{6}$ to $3.5 \times 10^{6}$ per foot, angle of attack 30 to 45 degrees. The data obtained were incorporated in the design of the thermal protection system of the orbiter [39, 40]. HUBE [41] used this technique to investigate possible consequences of losing one or more thermal protection tiles on the windward side of the orbiter. Besides project-oriented applications, general heating studies of elastomeric materials were carried out [42], the results glving insights to phenomena that were harder to access with other diagnostic tools. For example, In a testing program run at Mach $=10$, the surface heating was observed to be nonuniform to a greater extent than could have been forecast. Hot streaks that may be have been caused by wing-tip crossflow effects were detected, and increased heating rates were observed when local fallure of adhesive bonds formed bubbles in the substrate. Even though part of the data could not be reduced using the semi-infinite slab solution, the underlying assumptions being no longer valld, some of these effects could still be quantified, and operational conclusions could be drawn.

Tests under rarefied flow conditions at very high Mach numbers, say Mach $=20$, are characterized by a short duration of a very few seconds and heat fluxes that may get as low as $0.5 \mathrm{~kW} / \mathrm{m}^{2}$. In these cases, solid models may no longer be acceptable because there is not onough exposure time that is required for the temperature pattern to become established. For this application, thin-skin models and a conforming data reduction model may be the only way to get useful results [13]. BALAGEAS et al. [14-16, 43, 44] extended the use of thin-skin models to low Mach numbers (down to Mach $=2.0$ ) through stimulated thermography. According to this concept, a bank of lamps heats the wind-tunnel model over a pre-set period of time, and the heat transfer coefficient is determined from the temperature response of the model integrated over a period of time. This approach is less susceptible to curvature effects of the surface and noise, the data reduction being based on integration and not on differentiation.

Next to determination of heat fluxes, location of boundary-layer transition to turbulence is always a major subject of interest to aerodynamicists. Turbulent boundary layers have higher skin friction than the laminar ones. On the other hand, the laminar boundary layer is more susceptible to separation, especially in the super- and hypersonic regimes where shock-wave Interaction can cause strong adverse pressure gradients. With the increase in skin friction, the transition to turbulence also induces higher heat fluxes, and under some speed and flight time combination, the structure may require special thermal protection. Therefore, the capability to detect boundary-layer transition may have far-reaching consequences for the development and verification of designs.

One of two effects can cause the thermal signature of transition on a model. The first is the near-term thermal response of the model, occurring as long as it does not reach thermal equilibrium with the recovery temperature in the boundary layer. Under these circumstances, heat transfer takes place between the flow and the model and as a result, the area exposed to the turbulent regime is changing its temperature faster [2]. The second effect is the long-term response, occurring when the model and the surrounding flow come to quasi-steady thermal equilibrium. In this case, the wall temperature tends towards the adiabatic value, the latter being higher under the turbulent-versus-laminar boundary-layer regime.

PEAKE et al. [45] carried out a boundary-layer transition detection test in a blow-down tunnel at Mach $=3.85$ using a stainless steel flat plate equipped with a bakelite insert surface. The transition location appeared on the thermograms as a localized hot front that was attributed to the difference in the recovery temperature between the laminar and the turbulent regime; it was also confirmed by other experimental means. In a subsequent experiment, an all-stainless-steel 
flat plate painted black was used as target, but the distinct transition pattern could not be observed anymore. The relatively high thermal diffusivity of the metal that levels-out temperature differences along and in-depth through the model causes the inadequacy of the IR imaging technique to detect transition on stainless-steel models. In cases where the surface is polished, the situation is further aggravated. The high reflectance and the low emittance of the surface decrease the signal-to-noise ratio on the thermograms to an extent that renders the method useless. It may be speculated that at high Mach numbers the very intense heat transfer may offset the detriments of polished, stainless models by raising very rapidly the surface temperature to relatively high values. COLLIER et al. [46] tried this approach on a polished, stainless-steel cone at Mach $=14$ but no reliable temperature readings could be obtained. Later attempts to revert to a ceramic material produced temperature measurements that were in excellent agreement with thermocouple data [47].

Identifying the indication of transition on thermograms with a precise locus inside the evolving transition process is critical in evaluating the merit of the method. In more concrete terms, the problem is that on thermograms the transition to turbulence visually appears to happen abruptly, while actually the process may develop over a significant portion of the aerodynamic surface. HALL et al. [48] compared the diagnosis of transition from an IR imaging system with that of hot films on a flat plate at Mach numbers 1.5, 2.0 and 2.5. The results indicate that on thermograms the transition appears at various stages of its development. As expected, it always appears before the $50 \%$ intermittency; this detection intermittency value decreases as the Mach number increases.

Gortler vortices that occur in counter-rotating pairs on concave surfaces are another type of flow instability that lately have received renewed attention as they may occur on deflected flaps of space planes during atmospheric re-entry at hypersonic speeds. The prediction and understanding of the heat transfer this type of boundary-layer transition induces is of practical interest for the design of the thermal protection of the moving surfaces. BALAGEAS et al. [44] used IR imaging in an experiment at Mach $=10$ to map the surface heating pattern and temperature evolution, the heat transfer coefficients and the heat flux history. Their data, produced on a model made of an insulating material, indicate that heat transfer coefficients deduced from thermocouple measurements on a metallic model can be considerably lower than values deduced from IR imaging measurements, up to a factor of 2.5. CARLOMAGNO and DE LUCA [10] present similar patterns of Gortler vortices, where image-restoration techniques were successfully used to reconstruct the spatial details of the heating pattern. However, more work is needed to clarify what happens with the radiometric data on the thermograms as a result of the reconstruction process. Both these investigations were related to the European Hermes space-plane design. MAESTRELLO [49] used IR imaging to demonstrate that a turbulent boundary layer caused to Gortler vortices can be laminarized by localized heating.

Besides transition, flow separation and reattachment are features of much interest, especially on configurations of longitudinal symmetry. As the angle-of-attack increases, the flow will separate along the sides of the models, developing into large-scale vortices that reattach on the leeward side. These features are detectable through the surface temperature variation, minimum at separation and maximum at reattachment, and are induced by the respective behavior of the skin friction and heat transfer. BANDETTINI and PEAKE [50] carried out a separation detection study on a 10-degree fiberglass cone at different angles-of-attack at Mach $=1.8$, comparing the results with oil-flow visualization. Although the IR imaging and the oil flow visualization were performed at somewhat different Reynolds numbers $\left(3 \times 10^{6}\right.$ for the former and $9 \times 10^{6}$ for the latter, based on the model length), the vortices separation and reattachment could be identified on the thermograms as areas of higher and lower temperatures. Investigations of somewhat more complicated flows were carried out by ARAI and SATO [51] on a 12.84/7-degree, bent-nose biconic made of epoxy resin at various angles-of-attack at Mach $=7$, and by CARLOMAGNO and DE LUCA [10] on a double ellipsoid at Mach $=8.15$. The bent-nose biconic is a leading candidate for the forebody of the Aeroassisted Orbital Transfer Vehicle, and the double ellipsoid 
is representative of the European Hermes space-plane forebody. Both investigations produced results similar to those of BANDETTINI and PEAKE [50], confirming that vortical flow reattachment can cause heating on the leeward side of the vehicle at positive angles of attack (see also the SILTS experiment found under the section entitled Space Shuttle Experiments).

The experiments reviewed so far address temperature signatures of flow fields on models of circular geometry or longitudinal symmetry. Later, HENCKELS and MAURER [52] published the results of an experiment addressing a Mach $=8.7$ flow along a corner, produced by the intersection of two perpendicular plates, at various pitch and yaw angles. This is highly threedimensional flow, involving the interaction of two perpendicular shock waves originating at the leading-edge of each plate, and the formation of an embedded vortex underneath the slip surface produced by the interacting shocks. The thermograms were used to deduce heating rates on the walls, with the stipulation that the influence of the flow scaling on the results could not be inferred.

\section{Space shuttle flight experiments}

The Space Shuttle program deserves a special place in the history of IR imaging in aerodynamic engineering and research. As it was previously mentioned, the method was used during the engineering phase of the program to determine the atmospheric re-entry heating rates on its forebody. After the orbiters became operational, they were designated for two daring IR Imaging flight experiments aimed at mapping their surface heating during the actual re-entry phase.

In the InfraRed Imaging of the Shuttle (IRIS) experiment [53-55], the windward side of the Space Shuttle re-entering the atmosphere was observed from below through an astronomical If telescope mounted on a chasing C-141 aircraft, known as the Kuiper Airborne Observatory. Despite useful and promising results regarding the evolvment of the actual heating rates and the progression of the boundary-layer transition front [56], this experiment was discontinued because of its cost, the complex coordination work, and restricted availability of the airborne observatory.

In the Shuttle Infrared Leeside Temperature Sensing (SILTS) experiment, an IR imaging camera installed atop the vertical stabilizer of the Space Shuttle Columbia scanned the leeside of the orbiter during the atmospheric re-entry phase of some of its flights $[57,58]$. Zones of Intense heating were observed along the leading-edge and the upstream part of the wing, the inboard/outboard elevon gap, and the orbital maneuvering system pod [59-61]. In general, the heating pattern indicates a highly vortical flow, convecting high-temperature, compressed air from the windward side of the orbiter to its leeside. This behavior is typical of deltalike configurations at high angles of attack experiencing leading-edge flow separation. The real pay-off from this experiment could materialize if the heating patterns observed in flight would be reproduced in numerical simulations of the flow. Thereafter, the in-depth thermal response of the wing substrate could be analyzed in detail, expanding and enhancing the understanding necessary for future thermal protection designs. However, solving the complete time-dependent flow/heat transfer/heat conduction/radiation equations for the complete Space Shuttle configuration integrated in time over the re-entry time period is well beyond current computational capabilities.

Thermal protection of IR transparent windows by nitrogen film cooling is described by BRADLEY [62] in conjunction with the SILTS pod design, and by MORRIS et al. [63] in conjunction with endoatmospheric-interceptor sensor technology. 
http://dx.doi.org/10.21611/qirt.1992.011

\section{Sub- and transonic studies}

The possibility of using IR imaging for sub- and transonic aerodynamic research was raised only in the early eighties $[7,64]$. Since then, the application of this technique got to the point where some industrial wind-tunnels offer IR imaging scanning as part of their standard data acquisition process [65]. The interest in thermography for these flow regimes is mainly for boundary-layer transition research. The method is particularly attractive because it produces global views of the configurations of interest, mainly airfoils and wings, where the behavior of the boundary layer can be deduced through a quick visual inspection.

The preoccupation with laminar flow for drag reduction reappears periodically in aerodynamic research, mainly as a means for range extension. Starting in 1973, the global energy crisis has caused the subject to resurface. New designs of transport airplanes are required to reduce their fuel consumption and their resulting direct operating costs. One avenue that can be used to achieve this goal is to design the wings to sustain laminar boundary layers to the largest possible extent. In the current laminar flow research, the IR imaging technique is an integral part of the effort to make this aerodynamic technology available. The effort encompasses wind tunnel technology [66], wind tunnel and flight testing [67-69] and aerodynamic design philosophies [70-72]. The first mention of using IR imaging for transition detection in a transonic wind tunnel was made in ONERA's 1981 Activities [64]. One of the review's highlights is an experiment with an Airbus transport airplane model, where transition detection was attempted on both the model nose and the vertical tail, using the effect of the positive difference in the adiabatic wall temperature between the turbulent-versus-laminar regime. Because the vertical tail was metallic, further image enhancement was required to obtain clear transition demarcations. The vertical tail thermogram used in that review appears later in a paper by BoUCHARDY et al. [7], from ONERA Chatillon, where the processing methods used for the image enhancement are detailed. In the same year, GALKIN et al. [73] from TsAGI published results of extensive laminar flow experiments on epoxy-coated models. In these experiments, IR imaging was used alongside conventional measurement techniques and calculations to determine aerodynamic characteristics of supercritical airfoils, and particularly, the surface-roughness effects on the lift-to-drag ratio.

Current IR imaging systems are sensitive enough to detect transition down to Mach $=0.5$ in thermally stable wind tunnels, on models fabricated of thermally insulating materials, at ambient conditions. For lower air velocities, down to Mach $=0.1$, transition detection is still feasible through image processing enhancement of the thermograms. Among the thermally passive approaches to transition detection, the adiabatic wall temperature difference is the only aerodynamic effect that can be used in open circuit or thermally stable wind tunnels, where the stagnation temperature is considered constant [74]. QUAST [75] from DFVLR Braunschweig made a systematic investigation of transition detection in wind tunnels and flight testing. He pointed out that the increased heat transfer coefficient of the turbulent-versus-laminar regime is a remarkably useful attribute that makes the transition detectable on raw thermograms even at very low speeds, if the temperature of the model is different from the temperature of the flow. When exposed to this effect, the area underneath the transitional and turbulent boundary layer will change its temperature faster than its counterpart under the laminar regime, thus temporarily enhancing the temperature contrast between the two areas on the thermogram. The heat transfer effect is dominating the recovery temperature influence, and today it is used in the majority of transitiondetection experiments. It is convenient in use and interpretation, especially when implying the Reynolds analogy between convective heat transfer and skin friction coefficients. This effect occurs in closed-circuit wind tunnels, where the air heats naturally during their operation [76]. It can also be observed in wind tunnels equipped with a cooling system [75]. Another option is to use active heating of the model surface, electrical $[20,23,77]$, or laser [78], or to blow hot air through a hollow model $[24,25]$ and to observe the cooling effect of the flow. In flight testing, this effect occurs naturally when an airplane is flying an ascent or descent path through the atmosphere [67]. Although active heating of the substrate is very attractive and simple to 
http://dx.doi.org/10.21611/qirt.1992.011

Implement, the surface overheat value should be kept at the absolute necessary minimum to prevent a premature triggering of transition.

When the significance and potential of IR imaging became evident for boundary-layer research, the attention turned towards a full evaluation of the diagnostic capabilities of the method. In an effort to make the method more quantitative, it was shown that the active heating method can identify changes in the boundary-layer regime by tracking the behavior of the experimentally deduced heat transfer coefficient. Provided a laminar boundary layer is astablished downstream of the leading edge, the maximum heat transfer coefficient is indicative of transition to turbulence, and its following minimum occurs at separation [20, 23-26, 77-79]. If the passive method is applied, the transition is identified visually at the location of the step change in the surface temperature $[7,21,67,75,76,80,81]$. At higher incidence, the onset of turbulent separation is identified by the emergence of a second zone of increased heat transfer caused by local vorticity shedding [76]. However, this criterion indicates only the existence of separation, but does not indicate its surface extent. Qualitative separation and reattachment etudies on a slender body were carried out by CATTIN and JAGUSINSKI [82] using the passive detection method. A quantitative and more detailed separation and reattachment study was done by MONTI and ZUPPARDI [83], who used an internally heated, slender body model in conjunction with transient IR thermography. This approach allowed the identification of the heat transfer coefficients with the flow development over the model at different angles of attack.

The next step was to apply the IR imaging method to boundary-layer transition research, that eventually would lead to laminar airplane designs. For this application, one must be able to identify on the thermograms the various modes of boundary-layer transition, because the development of each mode can be attributed to a particular design feature of the wing under consideration. Generally speaking, at low Reynolds numbers and no sweep, the laminar boundary layer will separate under an adverse pressure gradient; the subsequent expansion of the flow will reattach the boundary layer as turbulent; and a laminar separation bubble will be contained in between the two regimes $[75,76]$. This bubble can be identified on thermograms as a narrow, elongated region of low heat transfer preceding the turbulent regime. At zero-tomoderate sweep and higher Reynolds number (but outside the critical conditions for attachment line transition), the transition will be caused by Tollmien-Schlichting waves characterized on the thermograms by a relatively smooth transition line [84]. As the sweep angle increases beyond a certain limit, the cross-flow mechanism will prevail, with the transition front on thermograms resembling a saw-teeth pattern [85].

The main obstacle to getting wider acceptance for this method, especially in the aeronautical Industry, is that models are usually made of aluminum or stainless steel of high quality surface flnish [86]. The problems mentioned with this type of model in the previous section, i.e., high thermal diffusivity, and low emittance and high reflectance, only render the method more difficult to apply. In some cases, the problem may be solved satisfactorily by applying an insulating film, 1 or $2 \mathrm{~mm}$ in thickness, in specially machined grooves [85]. CROWDER [81] suggested as a partial solution to this problem to cover the model with an insulating paint, and to spray liquid nitrogen into the tunnel, upstream of the test section. The rapidly cooling flow produces on the metallic surface a thermal effect that is strong enough to make transition visible. However, it is not clear if such high thermal gradients in the substrate do not influence the indication of the transition location on the thermograms.

Viewed in the perspective of a very few years, it seems that the IR imaging technique opened new horizons in laminar flow research and applications. The method was used extensively in wind tunnel and flight test programs in Germany by the DLR and Deutsche Airbus [84, 87-91], in France at ONERA [85, 92-95], and in USA at NASA [67, 80], to investigate the occurrence of the various transition modes. The DLR/Deutsche Airbus program was a particularly largescale effort. It combined flight tests on small- and medium-sized airplanes having laminar flow gloves mounted on the wings with wind-tunnel tests performed in different facilities. As part 
of this effort, an extensively instrumented VFW-614 twin-jet, medium-sized aircraft designated the Advanced Technologies Testing Aircraft System (ATTAS) was dedicated to laminar flow research over a period of a few years. The unique capability of IR imaging to provide repetitively global views of the transition pattern on the wing allowed an immediate identification of the prevailing mechanism under given test conditions. The combined use of IR imaging with hot films throughout the program helped elucidate the correlation between the actual mechanisms of transition development and numerical predictions designed to verify the $\mathrm{e}^{\mathrm{N}}$ method. At NASA, the effort focused on comparative flight testing of different competing, or supplementing, methods for transition research [67]. At ONERA, the technique was used to confirm designs specifically aimed at obtaining significant runs of laminar flow on aerodynamic surfaces [85]. Also, transition predictions were verified against flight results obtained from an airfoil installed atop a Dassault Falcon 50 (business jet) vertical stabilizer [92-94]. Unfortunately, none of these experiments illuminated the question surrounding the identification of the precise location in the transition process that this technique detects, even though it is generally accepted that this occurs around $50 \%$ intermittence indicated by hot films. The only exception was done by PELISSIER [96], who in a transition detection test on a $10^{\circ}$ cone, identified the beginning of the transition zone by correlating the locus of minimum surface temperature, at the end of the laminar run, with the locus of the raise of the RMS signal of hot films, obtaining excellent agreement between the two criteria. In this test, the IR imaging system was used in the line scan mode, for better frequency response.

The main drawback with transition studies made in conventional wind tunnels is the scale of the models and the resulting inconsistency between the Reynolds number of the model and that of the real flying airplane. This discrepancy is pivotal in the search for ground-testing methods capable of generating high Reynolds number flows. There are two main reasons for concern about this subject. The first is that transition, being a viscous effect, is critically influenced by the Reynolds number of the airplane in flight. The second is that as of yet, there are no proven scaling methods for flows, especially not at large Reynolds numbers. To solve this problem cryogenic wind tunnels have been devised where combinations of low temperatures, down to $100 \mathrm{~K}$, and moderate pressurization can generate flows with Reynolds numbers in excess of $10^{8}$ per meter. For these wind tunnels, non-intrusive, global and productive transition detection techniques are of fundamental importance. Despite the physical laws that govern IR radiation work against this application, the IR imaging method showed promising results [97], and so far, transition was detected at total flow temperatures down to $170 \mathrm{~K}[98,99]$.

\section{Propulsion and flow visualization studies}

The applications of IR imaging to propulsion studies are very diverse in nature, the technique being used in both cold-and hot-flow environments for studies ranging from flows in turbine cascades, through heat transfer measurements, to hot flows and plumes visualization.

\subsection{Cold flows}

One of the earliest applications to jet engine research was to study the effectiveness of film cooling for turbine blades $[100,101]$. In these applications the relative temperatures of the main flow and of the film flow are reversed. The cooling air that is injected through transpiration holes in the turbine blades is heated, to be visualized by IR imaging. This effect is possible because both the carbon dioxide and the water vapor in the air start to emit IR radiation at low overheat temperatures. Heat transfer studies for turbine blade cavities were carried out also by LEFEBVRE et al. [102] on an electrically heated model. The IR imaging was also used to inspect the filmcooled nozzle of a high-temperature wind tunnel for blockage areas on the transpiration surface [103]. 
BRAUNLING, QUAST, and DIETRICHS [104] used IR imaging to study boundary-layer/shock Interaction in a cascade flow simulating a jet engine turbine. This is an extension of transonic flow studies, the complex geometries complicating the flow and its diagnosis. The study succeeded In ldentifying laminar and turbulent boundary layers, shock waves, separation bubbles and longitudinal vortices on the blades, but more work will be required to elucidate the findings.

MANUEL et al. [105] performed a pure flow visualization study, using IR imaging to visualize wing-tip vortices of a flying airplane by injecting SF6 into their core.

\subsection{Hot flows}

HILTON [106] documented one of the earliest applications to jet-engine technology where IR Imaging was used to measure the temperature distribution on a jet-engine pipe at Rolls-Royce Aero Division. In that particular case, IR imaging proved to be an efficient and inexpensive means of ruling out the possibility that temperature gradients of the wall were responsible for causing troublesome distortions to a jet-engine pipe.

MEYERS et al. [107] used IR imaging in a comparative study of different film cooling concepts for jet-engine combustors. DECOINS and GIOVANNINI [108] and GIOVANNINI et al. $[109,110]$ showed that the film cooling effectiveness in combustors is strongly dependent upon the combined effect of the injection angle and the mass flow rate of the cooling gas.

Combustion gases present another opportunity for IR imaging research. STREBY [111], mapping the flow temperatures in an operating ramjet combustor, presented the temperature distribution of the reacting gases through topographic plots that helped analyze and interpret the data. BYINGTON et al. [112] used IR imaging to visualize and study the effectiveness of transpiration cooling in the hydrogen injection area of a supersonic combustor at flow temperatures up to $2000 \mathrm{~K}$. Their investigation produced a detailed picture of the flow, including the upstream shock interaction between the injected fuel and the main flow, the cool core of the injected fuel, and the lateral and downstream extent of the fuel-mixing zone.

IR imaging systems also have been used to visualize exhaust gases of jet engines. There was special interest in surveying the plumes of VTOL aircraft hovering close to ground [113, $114]$, because the interaction of the hot gases with the surrounding flow largely determines the aerodynamic capability and stability of these vehicles at take-off and landing. In a different application, the exhaust plume of a fighter aiplane on the ground was visualized to identify flow structures causing radiation of low-frequency acoustic waves [115]. Presumably, those waves were the source of trouble for electronic testing equipment placed nearby. PENDER and RouX [116] describe the development of a microcomputer-based IR imaging system for rocket plumes radiance measurements, including the algorithm used for radiance-field calibrations. AJDAR] et al. [117] and KRAEUTLE et al. [118, 119] determined the influence of various parameters on IR signatures of plumes; e.g., afterburning, nozzle shape, turbulence and solid carbon and aluminum oxide particles concentration. HARDMAN et al. [120] attempted to simulate computationally the radiance and temperature distribution of a combustion jet (5-in. diameter, $100 \mathrm{~m} / \mathrm{s}, 300^{\circ} \mathrm{C}$ ), and compare the results with a thermogram taken in the 2- to 5.6-micron short waveband. The numerical reconstruction of the jet used measured velocity and temperature distributions. Analysis of their results indicates that the translation of the thermograms radiance field to temperatures, and of the computed temperature distribution to radiance field was hampered by a lack of knowledge of the actual radiation constants of the exhaust gases.

\section{Heat transfer studies}

Relative to the obvious qualifications of the method for heat transfer studies, the scarcity of applications is relatively surprising. 
MERONEY [121] made a wind tunnel study of convective heat transfer of buildings using an actively heated model. The heat transfer coefficients were estimated, but lack of a data acquisition and processing system hampered progress on the work. PAGE et al. [122] investigated the flow of a radial jet on a stagnation surface. Using a heated jet impinging on a cold surface, they inferred the heat transfer occurring in the stagnation region from thermograms of the heated surface. CARLOMAGNO and DE LUCA $[19,123]$ performed a similar investigation with interest in the heat transfer of both a single jet and an array of jets. Earlier work on a single jet was done by BUCHLIN [124]. In these cases, however, a cold air flow impinged on a heated metallic foil. Another jet impingement experiment was performed by EPPICH and KREATSOULAS [125]. In their case, the surface upon which the jet impinged was a thin layer of an insulating material laid atop a constant temperature substrate. Therefore, they could deduce the heat flux across the top layer directly from the measurements of the surface temperature, the thickness of the top layer and the constant temperature of the substrate. GARTENBERG and ROBERTS [9] proposed a method of mapping velocities by measuring the temperature distribution along a thin, electrically heated wire placed across the flow of interest. The velocities can thus be derived from established convective heat transfer correlations, provided the error measurement of the IR imaging system is known. This holds true especially when the wire displays high-temperature gradients in the scanner field of view. BEDAT et al. [126] used a similar approach to deduce the temperature inside a flame by measuring the radiation from a silicon-carbide fiber with an IR imaging system operating in the line scan mode. SPENCE [127] examined the possibility of determining heat transfer coefficients on vanes used for missile thrust vector control from wind tunnel tests on a model vane under identical flow conditions. HENRY and GUFFOND [128] made temperature measurements on a helicopter blade in an icing tunnel to validate computer code predictions of de-icing effectiveness of blade heaters. DERSHOWITZ and HANSMAN [129] demonstrated the feasibility of using IR imaging to detect remote ice accretion on helicopter blades. BOVD [130] showed that in-flight IR thermography data can be used to verify temperature and heat-flux predictions for icing applications for both swept wings and propellers, and for heater testing. KLASSEN and DI MARZO [131] studied the solid-surface transient temperatures caused by the evaporation of a single droplet. The study was done to develop extinguishment models for burning solid surfaces; the influence of droplet size and shape on the evaporation time being investigated for both highand low-thermal conductivity materials. Other examples of heat transfer applications include convective heat transfer from a heated cylinder at moderate Reynolds numbers [132], external mapping of the temperatures of a gun barrel during firing [133] and monitoring of materials tested in arc jets [134].

\section{A view to the future}

A review of past achievements must end with a view to the future. Further progress in this field will be contingent on two factors: technical developments in IR imaging technology, and continuation of experimental exploration and aerodynamic research using this technique.

Current trends in the electro-optic and semiconductor industries point to future IR imaging systems incorporating focal plane detector arrays. Such systems will offer improved performance in terms of spatial resolution, temperature sensitivity, and frame rate generation. The frame rate performance is particularly critical for short duration hypersonic facilities, where hundreds of frames per second are required to adequately capture the thermal transients during a test [135, 136]. Optionally, these systems will trade higher frame rates for lower temperature sensitivity. In parallel, as increasingly powerful personal computers become available, they will be used to increase the frame rate acquisition and storage. This option will allow capture of faster thermal transients and promote the application of the method in very short test duration facilities. Currently, capture of fast temperature transients is possible only through one-dimensional line scanning [34, 137], thus loosing the advantages of the two-dimensional imaging technique. 
The testing needs at high Reynolds numbers in cryogenic wind tunnels at low temperatures will require imaging systems built around detectors sensitive to longer wavelength IR radiation, up to 36 micrometers $[97,138]$. In parallel, there will be requirements for window materials with high transmittance in selected bandwidths; good mechanical, thermal, and chemical properties; and compatible antireflective coatings.

At the hot-end of aerothermodynamic research, non-equilibrium, reactive, and hightemperature flow research will require multi-spectral IR imaging for measurement of wall thermal response, flow visualization, and tracing of the evolving concentration of chemical species through their absorption bands.

In aerodynamic testing, the challenge is either to solve the transition detection on metallic models or to compromise with other materials; either as inserts at locations of interest, or as model skins. The exact location where the transition is indicated on thermograms is still far from bolng defined. More comparative work is needed to define which phase of the transition process If detected, and to determine what flow, substrate, and IR imaging system parameters influence the identification of that location.

In general, each flow feature has a characteristic thermal signature that should be identifiable on thermograms of the models of interest. As the use of this technique expands, new features appearing on thermograms will puzzle engineers in their quest to identify their cause. Separation, shock waves, and vortices have already been observed and identified in the past, and continuing research will lead the IR imaging technique to become a widely accepted diagnostic tool in aerodynamic research.

\section{Conclusions}

In the years that have passed since 1967, infrared imaging of aerodynamic surfaces gained recognition as an experimental tool with a unique capability for fast mapping of surface temperatures. This capability is used in hypersonic research to determine heat-flux distributions from local temperature measurements and in subsonic research to give a global view of the boundarylayer transition to turbulence. With time, other flow features were identified on thermograms such as shock waves, separation, reattachment and vortices. The use of the technique was gradually expanded to other disciplines, most notably propulsion and basic heat transfer research.

The technique had a relatively slow start, because of sporadic experiments, obscure documentation and lack of data processing capability. When viewed in the perspective of the long period of time it took to mature and get recognition, it seems the technique was invented too soon. However, the ever-increasing number of publications reporting use of IR imaging in aerodynamic research is convincing proof that the method has passed through the development stage and is assuming the status of a routine experimental procedure.

\section{Acknowledgments}

This research was supported under NASA Langley Research Center grant NAS 1-18584-58. 


\section{REFERENCES}

[1] GARTENBERG (E.) and ROBERTS (A.S.) JR. - Twenty-five years of aerodynamic research with IR imaging, a survey. Thermosense XIII, An International Conference on Thermal applications and image diagnostic, SPIE, April 1991, p. 338-356; also Journal of Aircraft, Vol. 29, $\mathrm{N}^{\mathrm{O}} 2$, AIAA, March-April 1992, p. 161-171.

[2] SCHLICHTING (H.). - Boundary Layer Theory, 7th ed., p. 286, 334-335, 713-714, McGrawHill, New York, 1979.

[3] GARTENBERG (E.) and ROBERTS (A.S.) JR. - Phenomenological aspects of infrared imaging in aeronautical research. AIAA Paper 88-4674, September 1988.

[4] GAUSSORGUES (G.). - La Thermographie Infrarouge, 3rd ed., Technique et DocumentationLavoisier, 1989.

[5] LLOYD (J.M.). - Thermal Imaging Systems, Plenum Press, New York, 1975.

[6] GAUFFRE (G.) and FONTANELLA (J.-C.). - Les caméras infrarouges: principes, characterization, utilization. La Recherche Aerospatiale, ONERA, No 1980-4, p. 259-269; available also in English edition.

[7] BOUCHARDY (A.-M.), DURAND (G.) and GAUFFRE (G.). - Processing of infrared thermal images for aerodynamic research. Applications of Digital Image Processing, SPIE Vol. 397, April 1983, p. 304-309.

[8] ENAULT (C.), BRETAUDEAU (F.). - Traitement d'images de thermographie infrarouge: lissage local et interpolation temporelle. ONERA Rapport Technique 8/7254 SN, June 1988.

[9] GARTENBERG (E.) and ROBERTS (A.S.) JR. - Influence of temperature gradients on the measurement accuracy of IR imaging systems. International Conference on Thermal Sensing and Imaging Diagnostic Applications, Thermosense XII, SPIE Vol. 1313, April 1989, pp. 218-224; also Mapping flowfields and transition separation studies using an infrared imaging system. Journal of Aircraft, Vol. 28, $\mathrm{N}^{\circ}$ 4, AlAA, April 1991, p. 284-286; also 6th Applied Aerodynamics Conference, AIAA, June 1988, p. 121-128.

[10] CARLOMAGNO (G.M.) and DE LUCA (L.). - Infrared thermography for flow visualization and heat transfer measurements. Proceedings of Stato dell'Arte del Rilevamento con Camere Termiche nella Banda 8-14 Micron, Baccini \& Baldi, Firenze, Italia, Marzo 1991, p. 191-219.

[11] DE LUCA (L.), CARDONE (G.) and CARLOMAGNO (G.M.). - Theoretical and experimental analysis of the modulation response of a sampled IR imaging system. International Conference on Thermal Sensing and Imaging Diagnostic Applications, Thermosense XII, SPIE Vol. 1313, April 1989, p. 259-268.

[12] WOLFE (W.L.) and ZISSIS (G.J.), (ed). - Infrared Handbook, Environmental Research Institute of Michigan, 1985 , ch. 7.

[13] ALLEGRE (J.), DUBREUILH (X.H.) and RAFFIN (M.). - Measurement of aerodynamic heat rates by infrared thermographic technique at rarefied flow conditions. Rarefied Gas Dynamics: Physical Phenomena, Progress in Astronautics and Aeronautics, Vol. 117, AIAA, 1988, p. 157-167.

[14] BALAGEAS (D.), BOSCHER (D.), DEOM (A.), FOURNIER (J.) ET HENRY (R.). - La thermographie infrarouge: un outil quantitatif ă la disposition du thermicien, Revue Générale de Thermique, No 322 , October 1988, p. 501-510; also, ONERA T.P. No 1989-3, 1989. 
[15] BALAGEAS (D.), BOSCHER (D.), DELPECH (P.), DEOM (A.), FOURNIER (J.), GARDETTE (G.), LEMPEREUR (C.), BERTHOUMIEUX (P.) and ET MATHE (J.M.). - Application de la thermographie infrarouge a la mesure des flux thermiques en soufflerie. ONERA T.P. $N^{\circ}$ 1989-192, 1989.

[16] BALAGEAS (D.), BOSCHER (D.), DELPECH (P.) and DEOM (A.). - Détermination des coefficients de transfert convectif sur une maquette en soufflerie par thermographie infrarouge stimulée. ONERA T.P. No 1989-218, 1989.

[17] BALAGEAS (D.), DEOM (A.) and BOSCHER (D.). - La mesure de la température par caméra thermographique infrarouge. Revue Pratique de Contrôle Industriel Qualité, $N^{0} 164$, 1990, p. 61-74.

[18] CARLOMAGNO (G.M.). - Infrared thermography. Measurement Techniques in Hypersonic Flows, Lecture Series 1990-05, von Karman Institute for Fluid Dynamics, Rhode Saint-Genese, Belgium, May 1990, p. 1-27.

[19] CARLOMAGNO (G.M.) and DE LUCA (L.). - Infrared thermography in heat transfer. Handbook of Flow Visualization, Wen-Jei Yang editor, Hemisphere, New-York 1989, p. 531-553.

[20] CARLOMAGNO (G.M.), DE LUCA (L.) and ALZIARY (T.). - Heat transfer measurements with an infrared camera in hypersonic flow. Computers and Experiments in Fluid Flow, 4th International Conference on Computational Methods and Experimental Measurements, SpringerVerlag 1989, p. 467-476.

[21] GAUFFRE (G.). - Détection de la transition laminaire turbulent par thermographie infrarouge. La Recherche Aerospatiale, ONERA, No 1988-2, p. 11-22; available also in English edition.

[22] GIOVANNINI (A.). - Recent developments in non intrusive heat transfer measurements and temperature mapping using infrared thermographic systems and digital image processing. Heat Transfer in Single Phase Flows, Eurotherm Seminar $N^{\circ}$ 9, Bochum, Germany, July 1989, p. $59-67$.

[23] DE LUCA (L.), CARLOMAGNO (G.M.) and BURESTI (G.). - Boundary layer diagnostics by means of an infrared scanning radiometer. Experiments in Fluids, Vol. 9, Springer-Verlag, 1990, p. 121-128.

[24] MONTI (R.). - Thermography. in Flow Visualization and Digital Image Processing, Lecture Series 1986-09, von Karman Institute for Fluid Dynamics, Rhode Saint-Genese, Belgium, 1986.

[25] MONTI (R.). - Thermography. Handbook of Flow Visualization, Wen-Jei Yang editor, Hemisphere, New-York 1989, p. 331-353.

[26] SIMEONIDES (G.), VAN LIERDE (P.), VAN DER STIECHELE (J.), CAPRIOTTI (D.) and WENDT (J.F.). - Infrared thermography in blowdown and intermittent facilities. AlAA Paper 89-0042, 1989; see also, Journal of Thermophysics, Vol. 4, AIAA, April 1990, p. 143-148.

[27] SIMEONIDES (G.), VERMEULEN (J.P.), BOERRIGTER (H.L.) and WENDT (J.F.). Quantitative heat transfer measurements in hypersonic wind tunnels by means of infrared thermography. 14th International Congress on Instrumentation in Aerospace Facilities (ICIASF '91), IEEE, October 1991, p. 178-189.

[28] WENDT (J.F.). - Infrared thermography. in The Second Joint Europe/US Short Course in Hypersonics, U.S. Air Force Academy, Colorado Springs, January 1989.

[29] THOMANN (H.) and FRISK (B.). - Measurement of heat transfer with an infrared camera. Int. Journal Heat Mass Transfer, Vol. 11, 1968, p. 819-826. 
[30] ECKERT (E.R.G.) and DRAKE (R.M.) JR. - Analysis of Heat and Mass Transfer, 2nd. ed., McGraw-Hill, New-York, 1972, p. 169-172.

[31] JONES (R.A.) and HUNT (J.L.). - Use of fusible temperature indicators for obtaining quantitative aerodynamic heat-transfer data. NASA TR R-230, Washington D.C., February 1966.

[32] BALAGEAS (D.L.) and ORY (D.). - Improvements in the determination of convective transfers from infrared thermography. La Recherche Aerospatiale, Vol. 1980-3, ONERA, June 1980, p. 73-78.

[33] SCHEPERS (H.J.). - Heat transfer investigations of axisymmetric bodies at hypersonic speeds by means of infrared measurement. NASA TT F-14,509, Washington, D.C., August 1972. Translation from German of DLR-Mitt-71-19, October 1971.

[34] COMPTON (D.L.). - Convective heating measurement by means of an infrared camera. Space Shuttle Aerothermodynamics Technology Conference, Volume II-Heating, NASA TM $X-2507$, February 1972, p. 645-660; also Use of an infrared-imaging camera to obtain convective heating distributions. AIAA Journal, Vol. 10, August 1972, p. 1130-1132.

[35] BYNUM (D.S.), HUBE (F.K.), KEY (C.M.) and DYER (P.M.). - Measurement and mapping of aerodynamic heating in VKF Tunnel $B$ with an infrared camera. AEDC-TR-76-54, Arnold Air Force Station, Tennessee, November 1976.

[36] NOBLE (J.A.) and BOYLAN (D.E.). - Heat-transfer measurements on a 5-deg sharp cone using infrared scanning and on-board discrete sensor technique. AEDC-TR-78-V51, Arnold Air Force Station, Tennessee, December 1978.

[37] BOYLAN (D.E.), CARVER (D.B.), STALLINGS (D.W.) and TRIMMER (L.L.). - Measurement and mapping of aerodynamic heating using a remote infrared scanning camera in continuous wind tunnels. Proceedings 10th Aerodynamic Testing Conference, AIAA, April 1978, p. 213-231.

[38] STALLINGS (D.W.) and WHETSEL (R.G.). - Use of infrared imagery in continuous flow wind tunnels. Thermal Infrared Sensing Diagnostics, Thermosense V, SPIE Vol. 371, October 1982, p. 203-210.

[39] STALLINGS (D.W.) and CARVER (D.B.). - Infrared and phase-change paint measurements of heat transfer on the space shuttle orbiter. AEDC-TSR-78-V13, Arnold Air Force Station, Tennessee, June 1978.

[40] MARTINEZ (A.) and DYE (W.H.). - Results of test OH69 obtained in the AEDC VKF Hypersonic Tunnel $B$, using the infrared scanning method to obtain heat transfer data on the 0.040 scale model 82.0 of the space shuttle forebody. Vol. I and II, NASA CR-151410 and NASA CR-151141, July 1978.

[41] HUBE (F.K.). - Simulated thermal protection tile roughness effects on windward surface heat transfer on the Rockwell International Space Shuttle Orbiter. AEDC-TR-76-98, Arnold Air Force Station, Tennessee, January 1977.

[42] HENDER (D.R.) and OKABE (C.M.). - Expanded uses of infrared scanning data in aerodynamic heating tests. AIAA Paper 83-1542, June 1983.

[43] BALAGEAS (D.L.), BOSCHER (D.M.) and DEOM (A.A.). - Measurement of convective heat transfer coefficients on a wind tunnel model by passive and simulated infrared thermography. Infrared Technology XVI, SPIE Vol. 1341, 1990, p. 339-357. 
[44] BALAGEAS (D.), BOSCHER (D.), DEOM (A.) and GARDETTE (G.). - Heat transfer measurements in ONERA Super and Hypersonic Wind Tunnels using passive and active thermography. First European Symposium on Aerothermodynamics for Space Vehicles ESA/ESTCPU, Noordwijk, Netherlands, 1991, ONERA TP No 1991-51.

[45] PEAKE (D.J.), BOWKER (A.J.), LOCKYEAR (S.J.) and ELLIS (F.A.). - Non-obtrusive detection of transition region using an infra-red camera. in AGARD-CP-224, May 1977.

[46] COLLIER (A.S.), LAFFERTY (J.F.), SCOTT (S.S.) and WITTE (D.W.). - Aerodynamic heat transfer testing in hypersonic wind tunnels using an infrared imaging system. AlAA Paper 90-0189, January 1990.

[47] LAFFERTY (J.F.) and COLLIER (A.S.). - Infrared surface temperature measurements in NAVSWC's Hypervelocity Wind Tunnel No. 9. 14th international Congress on Instrumentation in Aerospace Simulation Facilities (ICIASF '91), IEEE, October 1991, p. 169-177.

[48] HALL (R.M.), OBARA (C.J.), CARRAWAY (D.L.), JOHNSON (C.B.), WRIGHT (R.E.) JR., COVELL (P.F.) and AZZAZY (M.). - Comparisons of boundary-layer transition measurement techniques in the langley unitary plan wind tunnel. AlAA Paper 89-2205, July 1989; also Comparison of boundary-layer transition measurement techniques at supersonic mach numbers. AIAA J., Vol. 29, N0 6, June 1991, p. 865-871.

[49] MAESTRELLO (L.). - Transition delay and relaminarization of turbulent flow. Instability and Transition, Hussaini, (M.Y.) and Voigt, (R.G.) editors, Vol. 1, Springer Verlag, New-York, 1990, p. 153-161.

[50] BANDETTINI (A.) and PEAKE (D.J.). - Diagnosis of separated flow regions on wind-tunnel models using an infrared camera. International Conference on Instrumentation in Aerospace Simulation Facilities, (ICIASF 79), IEEE, September 1979, p. 171-185.

[51] ARAI (N.) and SATO (K.). - Non intrusive measurement of surface temperature distributions. Sixteenth International Symposium on Space Technology and Science, AGNE Publishing, Tokyo, Vol. 1, Part 2, May 1988, p. 929-934.

[52] HENCKELS (A.) and MAURER (F.). - Application of infrared thermography in a hypersonic wind tunnel. International Conference on Instrumentation in Aerospace Facilities, (ICIASF 89), IEEE, September 1989, p. 516-524.

[53] Anonymous, Infrared Imagery of Shuttle (IRIS). Task 1 Final Report, Martin Marietta Corp., NASA CR-152123, August 1977.

[54] BYRON (S.L.) and EDSINGER (L.E.). - Preliminary analysis of remote infrared imagery of shuttle during entry an aerothermodynamic flight experiment. NASA TM 73251, Washington, D.C., August 1977.

[55] CHOCOL (C.J.). - Remote infrared imagery of shuttle during entry. Joint Automatic Control Conference, AlChE, June 1979, p. 251-255.

[56] GREEN (M.J.), BUDNIK (M.P.), YANG (L.) and CHIASSON (M.P.). - Supporting flight-data analysis for space-shuttle orbiter experiments at NASA Ames Research Center. NASA TM-84345, Washington, D.C., April 1983.

[57] MYRICK (D.L.) and KANTSIOS (A.G.). - Incorporating geometric and radiative effects into infrared scanning computer analysis. Thermosense V, SPIE Vol. 371, 1982, p. 211-215.

[58] THROCKMORTON (D.A.), ZOBY (E.V.) and KANTSIOS (A.G.). - The shuttle infrared leeside temperature sensing (SILTS) experiment. AIAA Paper 85-0328, January 1985. 
[59] THROCKMORTON (D.A.), DUNAVANT (J.C.) and MYRICK (D.L.). - Shuttle infrared leeside temperature sensing (SILTS) experiment-STS 61-C results. AIAA Paper 88-2668, June 1988.

[60] THROCKMORTON (D.A.), ZOBY (E.V.), DUNAVANT (J.C.) and MYRICK (D.L.). - Shuttle infrared leeside temperature sensing (SILTS) experiment-STS-28 preliminary results. AIAA Paper 90-1741, June 1990.

[61] THROCKMORTON (D.A.), ZOBY (E.V.), DUNAVANT (J.C.) and MYRICK (D.L.). - Shuttle infrared leeside temperature sensing (SILTS) experiment-STS-35 and STS-40 preliminary results. AIAA Paper 92-0126, January 1992.

[62] BRADLEY (P.). - An experimental investigation to determine the effect of window cooling by mass injection for the shuttle infrared leeside temperature sensing (SILTS) experiment. NASA TM 80170, September 1979.

[63] MORRIS (H.W.), MAJESKI (J.A.) and RAWLINSON (E.G.). - Development of IR sensor window cooling requirements for endoatmospheric interceptors. AIAA Paper 91-1439, June 1991.

[64] Anonymous, Activities 1981, Office National d'Etudes et de Recherches Aerospatiales, Chatillon-sous-Bagneux, France, 1981.

[65] ELSENAAR (A.), ROHNE (P.B.), ROZENDAL (D.) and POESTKOE (R.). - Instrumentation requirements for laminar flow research in the NLR high speed wind tunnel test. International Congress on Instrumentation in Aerospace Simulation Facilities (ICIASF 89), IEEE, September 1989, p. 365-373.

[66] ELSENAAR (A.). - The windtunnel as a tool for laminar flow research. 17th Congress of the International Council of the Aeronautical Sciences (ICAS 1990), AIAA, September 1990, p. 174-185. Enault, (C.) and Bretaudeau, (F.), Traitement d'images de thermographie infrarouge: lissage local et interpolation temporelle. ONERA Rapport Technique 8/7254 SN, June 1988.

[67] HOLMES (B.J.), OBARA (C.J.), MANUEL (G.S.) and LEE (C.C.). - Developments in flow visualization methods for flight research. Flow Visualization $V$, International Symposium, Hemisphere, Washington, D.C., 1990.

[68] KORNER (H.) and HORSTMANN (K.H.). - The use of airplanes for aerodynamic research at DFVLR-Institute for Design Aerodynamics. Festschrift for B.H. Gothert's 80 th Birthday, University of Tennessee, Space Institute, Tullahoma, October 1987.

[69] NITSCHE (W.) and SZODRUCH (J.). - Concepts and results for laminar flow research in wind tunnel and flight experiments. 17th Congress of the International Council of the Aeronautical Sciences (ICAS 1990), AIAA, September 1990, p. 197-209.

[70] GREFF (E.). - Aerodynamic design for a regional aircraft. 17th Congress of the International Council of the Aeronautical Sciences (ICAS 1990), AIAA, September 1990, p. 1251-1265.

[71] KORNER (H.), HORSTMANN (K.H.), KOSTER (H.), QUAST (A.) and REDEKER (G.). Laminarization of transport aircraft wings, A German View. AIAA Paper 87-0085, 1987.

[72] KORNER $(\mathrm{H}$.$) . - Natural laminar flow research for subsonic transport aircraft in FRG. 16th$ Congress of the International Council of the Aeronautical Sciences (ICAS 1988), AIAA, 1988.

[73] GALKIN (V.M.), ERMOLAEV (V.P.) and FOMIN (V.M.). - Experimental study of transition of the laminar boundary layer into turbulent. Soviet-French Group (TsAGI-ONERA) Meeting for Aerodynamics Aeroacoustics and Structures, The Zhukowski Center for Aero-Hydrodynamics, Moscow, 1983 (in Russian). 
[74] SCHMITT (R.L.) and SCHANETZ (B.P.). - Experimental investigation of three dimensional separation on an ellipsoid-cylinder body at incidence. AIAA Paper 85-1686, July 1985.

[75] QUAST (A.). - Detection of transition by infrared image technique. 12th International Congress on Instrumentation in Aerospace Facilities (ICIASF 87), IEEE, June 1987, p. 125-134; also Bestimmung des laminar-turbulent Umschlags mit Hilfe der Infrarottechnik, DFVLR Braunschweig IB 129 - 86/6, October 1987.

[76] GARTENBERG (E.), ROBERTS (A.S.) JR. and MCREE (G.J.). - Infrared imaging and tufts studies of boundary layer regimes on a NACA 0012 airfoil. 13th International Congress on Instrumentation in Aerospace Simulation Facilities (ICIASF 89), IEEE, September 1989, p. 168-178; also GARTENBERG (E.) and ROBERTS (A.S.) JR. - Airfoil transition and separation studies using an infrared imaging system. Journal of Aircraft, Vol. 28, No. 4, AlAA, April 1991, p. $225-230$.

[77] CARLOMAGNO (G.M.), DE LUCA (L.), BURESTI (G.), and LOMBARDI (G.). - Characterization of boundary layer conditions in wind tunnel tests through IR thermography imaging. Applications of Infrared Technology, SPIE Vol. 918, June 1988, p. 23-29.

[78] HEATH (D.M.), WINFREE (W.P.), CARRAWAY (D.L.) and HEYMAN (J.S.). - Remote non contacting measurements of heat transfer coefficients for detection of boundary layer transition In wind tunnel tests. 12th International Congress on Instrumentation in Aerospace Simulation Facilities (ICIASF '87), IEEE, September 1987, p. 135-139.

[79] MONTI (R.) and ZUPPARDI (G.). - Computerized thermographic technique for the detection of boundary layer separation. Aerodynamic Data Accuracy and Quality: Requirements and Capabilities in Wind Tunnel Testing, AGARD-CP-429, September 1987, Ch. 30.

[80] BRANDON (J.M.), MANUEL (G.S.), WRIGHT (R.E.) JR. and HOLMES (B.J.). - In-flight flow visualization using infrared imaging. AIAA Paper 88-2111, May 1988; also Journal of Aircraft, Vol. 27, AIAA, July 1990, p. 612-618.

[81] CROWDER (J.P.). - Infrared cameras for detection of boundary layer transition in transonic and subsonic wind tunnels. AlAA Paper 90-1450, June 1990.

[82] CATTIN (E.) and JAGUSINSKI (F.). - Thermographie infrarouge appliquée ă l'aérodynamique d'un corps fuselé. etude qualitative. R122/89, Institut Franco-Allemand de Recherches de SaintLouis, September 1989.

[83] MONTI (R.) and ZUPPARDI (G.). - Detecting 3-D turbulent separation regions using unsteady, computerized thermographic technique. 14th International Congress on Instrumentation in Aerospace Simulation Facilities (ICIASF '91), IEEE, October 1991, p. 49-59.

[84] HORSTMANN (K.H.), QUAST (A.) and REDEKER (G.). - Flight and wind-tunnel investigations on boundary-layer transition. 16th Congress of the International Council of the Aeronautical Sciences (ICAS 1988), AIAA, August 1988, p. 979-986; also Journal of Aircraft, Vol. 27, AIAA, February 1990, p. 146-150.

[85] SCHMITT (V.), RENEAUX (J.) and THIBERT (J.J.). - Design and experimental investigation of a laminar horizontal tail. AlAA Paper 90-3042, August 1990.

[86] CROWDER (J.P.). - Recent advances in flow visualization at Boeing commercial airplanes. Fifth International Symposium on Flow Visualization, Prague, Czechoslovakia, August 1989, Hemisphere, p. 573-583. 
[87] HENKE (R.), MUNCH (F.X.) and QUAST (A.). - Natural laminar flow: a wind tunnel test campaign and comparison with flight test data. 8th Applied Aerodynamics Conference, AIAA, 1990 , p. 393-400.

[88] HENKE (R.) and MUNCH (F.X.). - Laminar flow experiments with a large half model in transonic flow. 17th Congress of the International Council of the Aeronautical Sciences (ICAS 1990), AIAA, September 1990, p. 1090-1097.

[89] HORSTMANN (K.H.), REDEKER (G.), QUAST (A.), DRESSLER (U.) and BIELER (H.). Flight tests with a natural laminar flow glove on a transport aircraft. 8th Applied Aerodynamics Conference, AIAA, August 1990, p. 385-392.

[90] HORSTMANN (K.H.), REDEKER (G.) and MILEY (S.J.). - Flight investigations of TollmienSchlichting Waves on an aircraft wing. 17th Congress of the International Council of the Aeronautical Sciences (ICAS 1990), AIAA, September 1990, p. 186-192.

[91] REDEKER (G.), HORSTMANN (K.H.), KOSTER (H.), THIEDE (P.) and SZODRUCH (J.). Design of a natural laminar flow glove for a transport aircraft. 8th Applied Aerodynamics Conference, AIAA, August 1990, p. 375-384.

[92] MAREC (J.-P.). - Recherches de I'ONERA sur les avions civils. L'Aéronautique et l'Astronautique, $N^{\circ} 134,1989-1,1989$, p. 3-17.

[93] MAESTRATI (J.). - Aviation d'affaires et technologies nouvelles. L'Aéronautique et l'Astronautique, No 134, 1989-1, p. 32-34, 1989.

[94] JUILLEN (J.C.) and ARNAL (D.). - Moyens de detection et de mesure de la couche limite utilises au CERT/DERAT. Association Aéronautique et Astronautique de France, Note Technique No $89-14,1989,1989$.

[95] THIBERT (J.J.), RENEAUX (J.) and SCHMITT (V.). - ONERA activities on drag reduction. Ibid., 8th Applied Aerodynamics Conference, AlAA, August 1990, p. 1053-1064.

[96] PELISSIER (C.). - Détermination de la longueur de transition dans la soufflerie F1. ONERA Procěs-Verbal D'Essais No 1/8571 GY, May 1990.

[97] SERAUDIE (A.), BLANCHARD (A.) and DOR (J.B.). - Qualification d'essais en ambiance cryogénique à la soufflerie T2. presented at the 23eme Colloque d'Aérodynamique Appliquée, Association Aéronautique et Astronautique de France, Note Technique $N^{0}$ 86-07, Modane, Novembre 1986.

[98] GARTENBERG (E.), JOHNSON (W.G.) JR., JOHNSON (C.B.), CARRAWAY (D.L.) and WRIGHT (R.E.). - Transition detection studies in the cryogenic environment. 8th Applied Aerodynamics Conference, AlAA, August 1990, p. 234-244.

[99] GARTENBERG (E.) and WRIGHT (R.E.) JR. - Problems and solutions for transition detection in cryogenic wind tunnels by infrared imaging. 14th International Congress on Instrumentation in Aerospace Facilites, (ICIASF 91), IEEE, October 1991, p. 156-168.

[100] BLAIR (M.F.) and LANDER (R.D.). - New techniques for measuring film cooling effectiveness. Journal of Heat Transfer, ASME, Vol. 97, November 1975, p. 539-543.

[101] SASAKI (M.), KUMAGAI (T.) and HAMANO (M.). - Film cooling effectiveness for injection from multirow holes. Journal of Engineering for Power, ASME, Vol. 101, January 1979, p. 101-108. 
[102] LEFEBVRE (P.), PELLIER (P.), JOUAN (O.) and BEAUVOIT (A.). - Application de la thermographie infrarouge ă la détermination des coefficients d'echanges convectifs dans une cavité d'aube de turbine. Revue Francaise de Mécanique, Vol. 3, April 1990, p. 191-198.

[103] BORG (S.E.), WRIGHT (R.E.) JR., ALDERFER (D.W.) and WHIPPLE (J.C.). - The utllization of an infrared imaging system as a cooling slot blockage detector in the inspection of a transpiration cooled nozzle. NASA TM-102608, January 1990.

[104] BRAUNLING (W.), QUAST (A.) and DIETRICHS (H.-J.). - Detection of separation bubbles by infrared images in transonic turbine cascades. Journal of Turbomachinery, ASME, Vol. 110, October 1988, p. 504-511.

[105] MANUEL (G.S.), DARYABEIGI (K.), ALDERFER (D.W.) and OBARA (C.J.). - In-flight off-surface flow visualization using infrared imaging. SAE Paper $N^{\circ}$ 911006, April 1991.

[106] HILTON (A.). - Quantitative thermography in aero-engine research and development. Rolls-Royce Report PNR-90021, 1980.

[107] MEYERS (G.), VAN DER GEEST (J.), SANBORN (J.) and DAVIS (F.). - Comparison of advanced cooling concepts using color thermography. AIAA Paper 85-1289, July 1985.

[108] DECOINS (J.) and GIOVANNINI (A.). - Evaluation des échanges convectifs par thermographie infrarouge: validation et application au refroidissement de paroi. Actes de Colloque Thermique, Société Française des Thermiciens, Nantes, France, Mai 1990.

[109] GIOVANNINI (A.), MEURAT (A.) ET MILLAN (P.). - Etude du transfert sur une paroi munie de multiperforations. Actes du Colloque de Thermique, Société Française des Thermiciens, Belfort, France, Mai 1991.

[110] GIOVANNINI (A.), MEURAT (A.), MILLAN (P.) ET SERVAGE (J.L.). - Detailed heat transfer mappings around an isolated perforation hole. Eurotherm Seminar No 25, Pau, France, July 1991.

[111] STREBY (G.D.). - Combustor flow visualization using innovative infrared thermographic techniques. Wright Research Development Center WRDC-TR-89-2015, March 1989.

[112] BYINGTON (C.S.), NORTHAM (B.G.) and CAPRIOTTI (D.P.). - Transpiration cooling in the locality of a transverse fuel jet for supersonic combustors. AIAA Paper 90-2341, July 1990.

[113] FLAIG (J.W.). - Infrared flow visualization for VTOL applications. AIAA Paper 77-618, June 1977; also USN/FMOD FRG VAK-191K Joint Flight Test Program, Volume 13, IR Flow Visualization. Naval Air Systems Command NAVAIR-13R-76, August 1976.

[114] DRIES (J.W.) and FERRANTE (J.). - Exhaust flow visualization of the McDonnell-Douglas Lift/Cruise Fan V/STOL Aircraft model. Naval Research Laboratory Instruction Book 174, Washington, D.C., February 1980.

[115] WITTEN (A.J.) and COURVILLE (G.E.). - Investigation of aeroacoustic mechanisms by remote thermal imaging. Thermal Infrared Sensing for Diagnostic and Control, Thermosense $X$, SPIE Vol. 934, April 1988, p. 207-214.

[116] PENDER (C.W.) JR. and ROUX (J.A.) - Microcomputer system for controlling an infrared scanning camera. Microcomputers and Microprocessors in Optical Systems, SPIE Vol. 230, 1980 , p. 120-129.

[117] AJDARI (E.), GUTMARK (E.), PARR (T.P.), WILSON (K.J.) and SCHADOW (K.C.). Thermal imaging of afterburning plumes. AIAA Paper 89-0062, January 1989. 
[118] KRAEUTLE (K.J.), WILSON (K.J.), LEE (M.J.), MATHEWS (L.A.), STALNAKER (R.A.) and SCHADOW (K.C.). - The effect of particles on afterburning and thermal images of plumes. AIAA Paper 91-0182, January 1991.

[119] KRAEUTLE (K.J.), WILSON (K.J.), LEE (M.J.), YU (K.H.), GUTMARK (E.) and SCHADOW (K.C.). - Effect of carbon particles and mixing on afterburning of exhaust plumes. AlAA Paper 92-0767, January 1992.

[120] HARDMAN (R.R.), SMITH (M.H.), GELHAUSEN (P.A.), VAN DALSEM (W.R.) and MAHAN (J.R.). - Infrared imaging: a validation technique for computational fluid dynamics codes used in STOVL applications. AIAA Paper 91-0675, January 1991; also Hardman, (R.R.). - Infrared imaging: a proposed validation technique for computational fluid dynamics codes used in STOVL applications. M.S. Thesis, Virginia Polytechnic Institute and State University, Blacksburg, Virginia, May 1990.

[121] MERONEY (R.N.). - Studying the convective heat transfer from a building model with infrared camera techniques. ASME Transaction 78-WA/HI-58, 1978.

[122] PAGE (R.H.), OSTOWARI (C.) and CARBONE (J.S.). - Radial jet flow. Flow Visualization IV, International Symposium, Hemisphere, Washington, D.C., 1987, p. 513-521.

[123] CARLOMAGNO (G.M.) and DE LUCA (L.). - Heat transfer measurements by means of infrared thermography. International Symposium on Flow Visualization IV, Hemisphere, Washington D.C., 1987, p. 611-616.

[124] BUCHLIN (J.-M.). - Thermography application to heat transfer of impinging jets. Flow Visualization and Digital Image Processing, Lecture Series 1986-09, von Karman Institute for Fluid Dynamics, Rhode Saint-Genese, Belgium, June 1986, p. 13-22.

[125] EPPICH (H.M.) and KREATSOULAS (J.C.). - A novel infrared thermography heat transfer measurement technique. AIAA Paper 89-0601, January 1989.

[126] BEDAT (B.), GIOVANNINI (A.) and PAUZIN (S.). - Instantaneous temperature profile measurements in a flame by infrared line thermometry technique. Eurotherm Seminar $N^{\circ} 17$, Cascais, Portugal. October 1990.

[127] SPENCE (T.M.). - Applications of infrared thermography in convective heat transfer. M.S. Mech. Eng. Thesis, Naval Postgraduate School, Monterey, March 1986.

[128] HENRY (R.) and GUFFOND (D.). - Infrared technique to measure skin temperature on an electrothermal de-icer, comparison with numerical simulations. AIAA Paper 89-1989, ONERA TP No 1989-4, January 1989; see also ONERA TP 1989-28.

[129] DERSHOWITZ (A.) and HANSMAN (R.J.). - Experimental investigation of passive infrared ice detection for helicopter applications. AIAA Paper 91-0667, January 1991.

[130] BOYD (L.S.). - Analysis of infrared thermography data for icing applications. AIAA Paper 91-0666, January 1991.

[131] KLASSEN (M.) and DI MARZO (M.). - Transient cooling of a hot surface by droplet evaporation. National Institute of Standards and Technology NIST-GCR-90-575, Gaithersburg, MD., May 1990.

[132] DARYABEIGI (K.) and ALDERFER (D.W.). - Aerodynamic applications of infrared thermography. 33rd International Technical Symposium on Optical and Optoelectronic Applied Science and Engineering, SPIE Paper 1157-20, August 1989. 


\section{http://dx.doi.org/10.21611/qirt.1992.011}

[133] FULLER (P.W.W.). - Gun barrel temperature study using short time scan thermal imaging. 13 th International Congress on Instrumentation in Aerospace Simulation Facilities (ICIASF 89), 13th IEEE, September 1989, p. 159-167.

[134] WHITE (S.M.) and BURLEIGH (D.). - Thermographic monitoring of materials under simulated reentry conditions. AIAA Paper 91-0696, January 1991.

[135] CHEVALIER (J.P.), CHRISTOPHE (J.) and GIRARD (A.). - High enthalpy hypersonic wind tunnel F4: general description and associated instrumentation. Test and Measurement Technique in Hypersonics, Technische Univ., Berlin, Germany, 1989, p. 41-57.

[136] GIRARD (A.), BOUTIER (A.), CHEVALIER (J.P.) ET FRANCOIS (G.). - Instrumentation en cours de développement pour la soufflerie $F 4$ de l'ONERA. presented at the $26^{\mathrm{e}}$ Colloque d'Aérodynamique Appliquée, Association Aéronautique et Astronautique de France, Note Technique $\mathrm{N}^{\mathrm{O}} 89-11$, Octobre 1989.

[137] HENCKELS (A.), MAURER (F.), OLIVIER (H.) and GROENIG (H.). - Fast temperature measurement by infrared line scanning in a hypersonic shock tunnel. Experiments in Fluids, Springer-Verlag Vol. 9, July 1990, p. 298-300.

[138] SCHULZE (B.), LANGE (R.) and CRAUBNER (S.). - An infrared camera system for detection of boundary layer transition in the ETW. 2nd Cryogenic Technology Meeting, European Transonic Windtunnel GmbH and DFVLR, Koln, Germany, June 1988. 